\title{
Kronik Ruhsal Hastalığı Olan Bireylerde Diyabet Yönetimi ve Psikiyatri Hemşiresinin Rolü
}

\author{
Sevecen ÇELIK İNCE *, Neslihan PARTLAK GÜNÜŞEN **
}

Öz

Diabetus mellitus dirençli hiperglisemi ile karakterize kompleks metabolik bir bozukluktur. Kronik ruhsal hastalı̆̆ı olan bireylerde diyabet görülme oranı sağlıklı popülasyona göre daha yüksektir. Genetik ve yaşam biçimini içeren birçok faktöre bağlı olarak geliştiği bilinen tip 2 diyabetin, ikinci kuşak antipsikotik ilaçların kilo artışı, glikoz metabolizma bozuklukları gibi yan etkisi nedeniyle kronik ruhsal hastalığı olan bireylerde görülme riski artmaktadır. Diyabet yönetiminde sağlıklı yaşam biçimini teşvik etme, tarama ve izleme tedavinin önemli parçasıdır. Kronik ruhsal hastalığı olan bireylerde diyabet oranlarındaki bu artış ve hastaların her iki hastalığı yönetmelerinde yaşadığı zorluklar sağlık bakımında yeni yaklaşımları gerektirmektedir. Bu derlemenin amacı kronik ruhsal hastalığı olan bireylerde diyabet sıklığının, yönetiminin nasıl olduğuna ve psikiyatri hemşirelerinin rollerine 1şık tutmaktır.

Anahtar kelimeler: Diabetes Mellitus, Psikiyatri Hemşireliği, Ruhsal Hastalık.

\section{Diabetes Management in Individuals with Severe Mental Illness and the Role of the Psychiatric Nurse}

Diabetes Mellitus is a complex metabolic disorder characterized by resistant hyperglycemia. The prevalence of diabetes in individuals with severe mental illness is higher than in the healthy population. Diabetes Mellitus is known to develop due to several factors including genetics and lifestyle. In addition, the risk of diabetes is increased due to the side effects of second generation antipsychotic drugs, such as weight gain, glucose metabolism disorders, used by individuals with severe mental illness. Promoting a healthy lifestyle in diabetes management, screening and monitoring patients is an important part of the treatment. This increase in the rates of diabetes in individuals with severe mental illness and the difficulties that patients have in managing both illness require new approaches in health care. The purpose of this review is to shed light on the prevalence and the management of diabetes in individuals with severe mental illness and on the roles of psychiatric nurses.

Key Words: Diabetes Mellitus, Psychiatric Nursing, Mental Illness.

Geliș tarihi: 26.11.2019

Kabul tarihi: 23.05.2020

$\mathrm{T}$ Tip 2 diyabet insülin salınımı, insülin etkisi ya da protein, karbonhidrat ve yağ metabolizmasında dengesizlik sonucu kanda hiperglisemi ile kendini gösteren, her yaştaki bireyde görülebilen, yaşam boyu devam edebilen, kompleks, kronik, fiziksel bir hastalıktır $(1,2)$. Dünya Sağlık Örgütü, diyabeti, kronik hastalıklar içinde önemli bir yerde görmekte ve yeni bin yılın en önemli sağlık sorunları arasında kabul etmektedir (3). Küresel boyutta 347 milyon insanın diyabet tanısına sahip olduğu, 2013 yılında 5.1 milyon kişinin diyabet nedeniyle öldüğü ve yaklaşık 2030 y1lında diyabetten ölümlerin iki katına çıkacağı belirtilmiştir (4). Türkiye İstatistik Kurumu (TUIK) verilerine göre ise ülkemizde 15 yaş ve üzeri nüfusun \%6.7'sinin diyabet tanısı aldığı belirtilmiştir (5). Diyabet hastalığı sonucu meydana gelen hiperglisemi önlenemediğinde akut (ketoasidoz, laktik asidoz vb) ve kronik (retinopati, nefropati, nöropati, kardiyovasküler hastalıklar vb) komplikasyonlar ortaya çıkabilmekte, miyokart enfarktüsü, ampütasyon hatta mortalite meydana gelebilmektedir $(1,6,7)$. Diyabetin obezite, fiziksel aktivite yetersizliği, ileri yaş, sağlıksız ve yetersiz beslenme, ailede diyabet öyküsü olması gibi birkaç önemli risk faktörü olduğu belirtilmektedir $(2,4)$. Bu nedenle diyabet bakımının amacı kan glikoz seviyesini normal sınırlar içinde tutarak, olası komplikasyonları önlemektir. Bu bağlamda diyabet bakımının beş unsuru; hastada diyabete yönelik beslenmenin sağlanması, fiziksel aktivitenin artırılması, hastanın kendi kan glikoz düzeyini izlemesi, hastanın diyabet öz bakımı ile ilgili eğitilmesi ve ilaç tedavisinin düzenli devam ettirilmesidir (7).

Bipolar bozukluk, majör depresif bozukluk, şizofreni gibi kronik ruhsal hastalığı olan bireylerde ruhsal hastalıklarının yanı sıra yaşam kalitesini azaltabilen diyabet, kardiyovasküler hastalıklar, solunum sistemi hastalıkları, bazı kanser türleri gibi önemli fiziksel sağlık sorunları görülebilmekte ve genel nüfusa oranla yaşam beklentisi 8-32 yıla kadar azalmaktadır (8-10). Ayrıca kronik ruhsal hastalığı olan bireylerde genel nüfusa oranla akut metabolik komplikasyon, bozulmuş glikoz toleransı, insülin direnci ve tip 2 diyabet gelişme olasılığının daha yüksek $(9,11)$ ve diyabet nedeniyle mortalite olasılığının altı kat daha fazla olduğu belirtilmektedir $(8,12)$. Vinogradova ve arkadaşlarının (2010), diyabet tanısına ek olarak şizofreni, bipolar bozukluk gibi kronik ruhsal hastalık tanısı olan bireyler ile yalnızca diyabet tanısı olan bireylerde sağ kalım oranlarını inceledikleri çalışmanın sonucunda, ruhsal hastalık ve diyabeti olanların yalnızca diyabeti olan hastalara göre mortalite oranlarının daha yüksek olduğu bulunmuştur (13).

Bu derlemenin amacı kronik ruhsal hastalığı olan bireylerde diyabet sıklığının, diyabet yönetiminin nasıl olduğuna ve psikiyatri hemşirelerinin rollerine 1şık tutmaktır.

\section{Gelişme
Kronik Ruhsal Hastalı̆̆
Olan Bireylerde Tip 2 Diyabet Sıklı̆̆ ve Nedenleri}

Genel nüfusta tip 2 diyabet vakalarının yaklaşık \%25'i teşhis edilemezken, kronik ruhsal hastalığı olan bireylerde tip 2 diyabet vakalarının \%70'inin teşhis edilmediği bildirilmektedir (12). Kronik ruhsal hastalığı olan bireylerin yaklaşık \%10-15'i tip 2 diyabete sahiptir $(12,14)$. Ülkemizde kronik ruhsal hastalığı olan bireylerde diyabet oranlarını belirleyen çalışmalara ulaşılamamıştır. Uluslararası literatürde kronik ruhsal hastalığı olan bireylerde tip 2 diyabet görülme sıklığını belirlemek için

*Dr. Zonguldak Bülent Ecevit Üniversitesi Sağlık Bilimleri Fakültesi Psikiyatri Hemşireliği Anabilim Dalı, Zonguldak. E-posta: sevecencelik@hotmail.com, sevecencelik@ beun.edu.tr, ORCID: 0000-0003-3113-4565, ** Doç. Dr. Dokuz Eylül Üniversitesi Hemşirelik Fakültesi Psikiyatri Hemşireliği Anabilim Dalı, İzmir. ORCID: 0000-0002-1666-291X. 
yapılan çalışma sonuçları değişiklik göstermekle birlikte bu oranın bu bireylerde $\% 10-25$ arasında değişiklik gösterdiği tahmin edilmektedir (12). Subashini ve arkadaşlarının (2011) çalışmasında diyabet görülme sıklığının şizofreni tanılı bireylerde (\%15.3) şizofreni tanısı olmayan bireylere göre (\%7.3) daha yüksek olduğu belirtilmiştir (15). Genel olarak bakıldığında; bipolar bozuklukta diyabet yaygınlığı genel nüfusa oranla iki kat daha fazla olduğu bildirilmektedir (16).

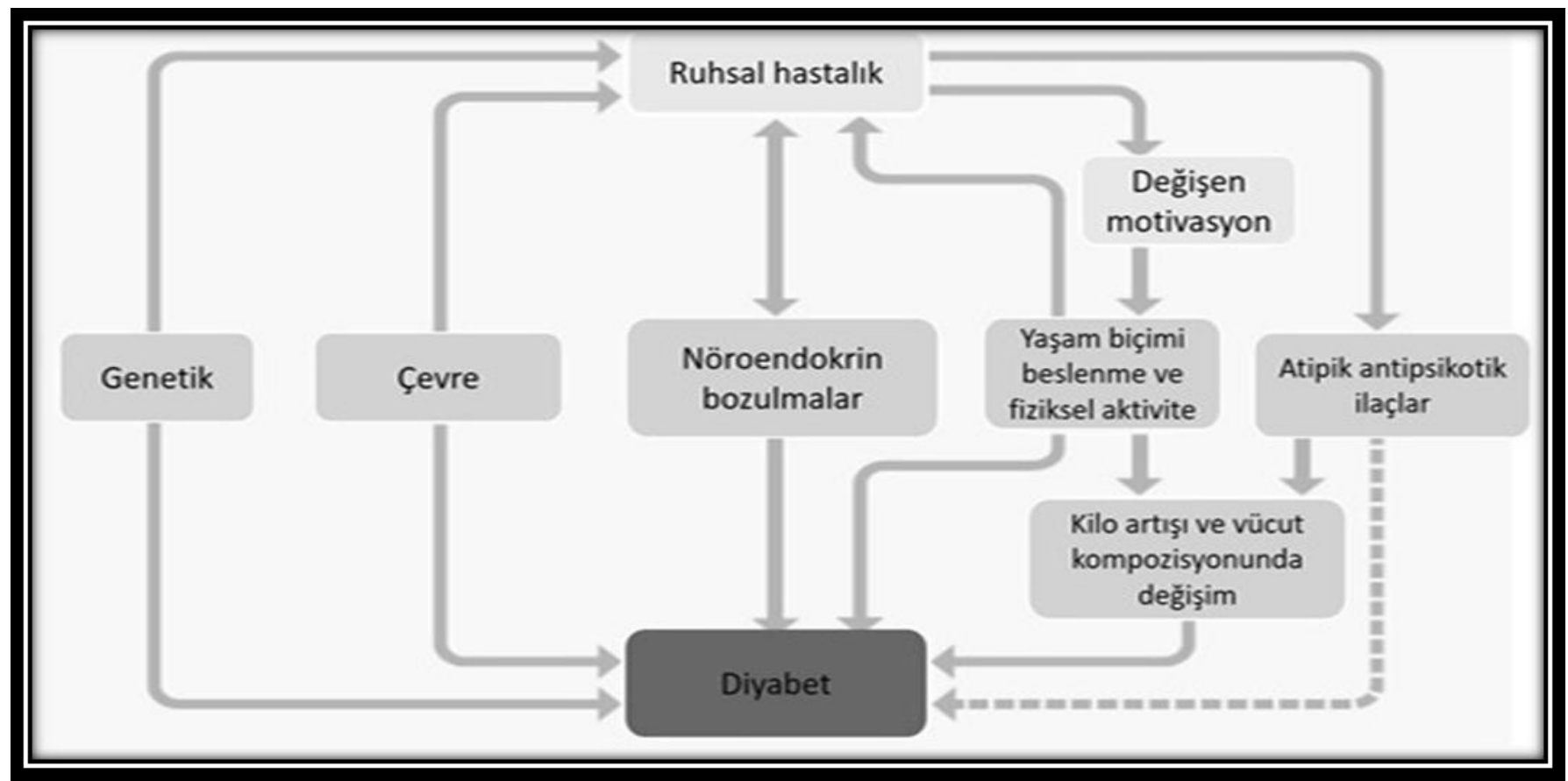

Şekil 1. Diyabet ve Kronik Ruhsal Hastalık Arasındaki İlişkinin Temelini Oluşturan Mekanizmalar (12)

Diyabet ve kronik ruhsal hastalık arasındaki ilişkinin temelini oluşturan mekanizmalar çok faktörlüdür (Şekil 1). Bunlar, genetik, yaşam tarzı (zayıf beslenme, fiziksel hareketsizlik ve sigara içme), biyolojik (depresyon gibi) ve tedavi ile ilişkili faktörleri içermektedir (12). Kronik ruhsal hastalığı olan bireylerde fazla kalorili beslenme, az lifli beslenme, fiziksel aktivite eksikliği ve sigara tüketimi gibi sağlıksız yaşam alışkanlıkları yüksektir $(17,18)$. Kronik ruhsal hastalığı olan bireylerin yaşadıkları psikiyatrik semptomlar (depresif duygudurum, halüsinasyon ve sanrılar) fiziksel aktivite yapma motivasyonlarını olumsuz etkilemekte (17), sağlıksız yaşam biçimi bu bireylerin kilo artışını desteklemekte ve diyabet gelişme riskini arttırmaktadır (9,11). Ayrıca bu bireylerin kullandıkları özellikle ikinci kuşak antipsikotik ilaçlar iştah artışına, sedasyona, kan lipid düzeyinde artışa ve glikoz metabolizmasında bozulmaya neden olmaktadır (10,19). Yapılan bir derlemede psikoz hastalarında antipsikotik kullanılmaya başlandıktan sonra antipsikotiklerin, kilo alımı ve insülin duyarlılığı ile sekresyonunu doğrudan etkileyerek diyabet riskini artırdığı saptanmıştır (20). Kronik ruhsal hastalıklarda kullanılan diğer ilaç grupları olan antidepresan ve duygudurum düzenleyici ilaçlar ile diyabet arasındaki ilişki hakkında literatürde farklı sonuçlar olmasına karşın, bu ilaçların uzun süre kullanımına bağlı diyabet gelişme riskinin arttığı belirtilmektedir $(21,22)$ Yoon ve arkadaşlarının (2013), antidepresan kullanımı ile diyabet riskini değerlendirdikleri meta analiz çalışmasının sonucunda antidepresanların (özellikle serotonin geri alım inhibitörleri) kilo artışı yan etkisi ile diyabet riskini arttırdıkları saptanmıştır (23). Yapılan bir başka sistematik derlemede antidepresanların kullanımının glikoz disregülasyonunu arttırdığı ve özellikle duygudurum düzenleyici ilaçlardan valproik asitin insülin direnci gelişimine neden olması ile diyabet gelişme riskini arttırdığı saptanmıştır (22).

Amerikan Diyabet Derneği, antipsikotik ilaçlarla tedavi edilen hastalar için yıllık diyabet taraması yapılmasını önermektedir (24). Bu artan klinik ihtiyaca rağmen, kronik ruhsal hastalığı olan bireyler, diyabet ve kardiyovasküler risk faktörleri açısından daha az taranmakta, kardiyovasküler riskleri önleyici hizmetler bu bireylere daha az sunulmakta ve bu bireylerin diyabet eğitimi alma olasılığı daha düşük olmaktadır (12). Kronik ruhsal hastalığı olan ve olmayan diyabetli hastalara sunulan diyabet bakımının kalitesini belirlemek için yapılan bir çalışmada kronik ruhsal hastalığın yanı sıra diyabeti olan bireylerin sağlık bakımı sunanlardan diyabetle ilgili, kan glikoz seviyesini izleme ile ilgili daha az eğitim aldıkları saptanmıştır (11). Yetersiz sağlık hizmetinin nedeni hasta ve hastalıktan kaynaklı, tedavi ve sağlık çalışanlarından kaynaklı olabilen çok boyutlu engeller ile açıklanmaktadır (25). Hasta ve hastalık kaynaklı engeller; hastada ortaya çıkan bilişsel bozulma nedeniyle diyabet belirtileri gibi fiziksel sorunları fark edememe, şüphecilik gibi psikiyatrik semptomlar nedeniyle yeterli fiziksel sağlık bakımı aramama ve sağlık bakım önerilerine uymada zorlanma, sağlıksız yaşam biçimi alışkanlıklarına sahip olma gibi engellerdir (25). Tedaviyle ilgili engeller, özellikle psikotrop ilaçların fiziksel sağlı üzerindeki yan etkileridir. Sağlık çalışanlarına ilişkin engeller ise, hastalarla yeterli iletişim kurmama, fiziksel hastalıktan çok psikiyatrik hastalığa odaklanma, psikiyatri alanındaki sağlık bakımı sunanların fiziksel sağlık bakımı sunmaya ilişkin bilgi eksikliği olması ve fiziksel yakınmaları psikosomatik yakınma olarak görme vb. sayılabilmektedir $(26,27)$. 
Kronik ruhsal hastalığı ve tip 2 diyabeti olan bireyler hem psikiyatrik hastalık yükü ile başa çıkmaya çalışırken hem de psikiyatrik semptomlara ek olarak diyabet semptomları ile baş etmek zorunda kalmaktadırlar (25). Diyabet tanısına sahip olan bireyler kendi diyabete özgü beslenme, fiziksel aktivite yapma, kendi kan şekerini izleme, diyabet tedavisine uyma, diyabet kontrollerine düzenli gitme, ayak bakımı yapma gibi diyabet öz bakım aktivitelerini yapmak ve takip etmek durumundadırlar (25). Diyabeti olan kronik ruhsal hastalığı olan bireylerin bu öz bakım aktivitelerini yapması ve bu konuda desteklenmesi oldukça önemli olup psikiyatri hemşirelerine önemli bir rol düşmektedir.

Son yıllarda uluslararası literatürde bu bireylerin diyabet öz bakımlarının nasıl olduğuna dair sorular gündeme gelmiş olup, konuya ilişkin bazı çalışmaların yapıldı̆̆ı göze çarpmaktadır $(17,25)$. Yapılan çalışmalarda kronik ruhsal hastalığa ek olarak diyabeti olan bireylerin diyabet öz bakım aktivitelerini yerine getirmekle ilgili bazı engeller yaşadıkları belirlenmiştir. Mulligan ve arkadaşları (2017) kronik ruhsal hastalığa ek olarak tip 2 diyabeti olan 14 birey ile diyabeti yönetmedeki engellerini belirlemek için kalitatif bir çalışma yapmışlardır. Çalışmalarının sonucunda hastaların duygu durumlarının düşük olması, bilişsel yıkımları nedeniyle hatırlamakta zorluk yaşamaları, diyabet komplikasyonlarına yönelik bilgi eksikliklerinin olması ve psikotik semptomları yaşamalarının diyabeti yönetmede engel oluşturduğu saptanmıştır (28). İnce ve arkadaşlarının (2017) yaptığı nitel çalışma kronik ruhsal hastalığı olan bireylerin psikiyatrik semptomlar (halüsinasyon ve sanrılar), psikotrop ilaç yan etkileri, diyabet ile ilgili yeterli bilgiye sahip olmama, sağlık ekibinin ve aile üyelerinin olumsuz tutumları nedeniyle diyabete yönelik özbakımlarının engellendiği belirlenmiştir (25). Hem şizofreni hem de tip 2 diyabet tanılı bireylerde yapılan başka bir çalışmada ise şizofreni hastalarının beslenme, fiziksel aktivite ve kan şekeri ölçümü açısından öz bakım skorlarının önemli derecede düşük olduğu bulunmuştur (17). Çalışma sonuçları kronik ruhsal hastalığı olan bireylerin diyabet yönetiminde sorunlar olduğunu göstermektedir. Bu bağlamda kronik ruhsal hastalığı olan bireyler ile çalışan psikiyatri hemşirelerine bütüncül bakım çerçevesinde önemli sorumluluklar düşmektedir.

\section{Kronik Ruhsal Hastalı̆̆ı olan Bireylerde Diyabet Yönetiminde Psikiyatri Hemşirelerinin Sorumlulukları}

Kronik ruhsal hastalığı ve diyabet tanısı olan bireylere yönelik verilecek sağlık bakımı psikiyatri hemşiresi, psikiyatri hekimi, diyabet hemşiresi, endokrin hekimi, diyetisyeni ve diğer sağlık görevlilerini içeren multidisipliner ekip işbirliğini gerektirmektedir $(14,17,29,30)$. Bu bireyler, diyabet gibi fiziksel sağlık sorunlarını tanımlamada, izlemede ve yönetebilmede psikiyatri hemşirelerinin desteğine ihtiyaç duyabilmektedirler (31). Psikiyatri hemşireleri bütüncül bakım kapsamında kronik ruhsal hastalığı olan bireylerde yaygın olarak görülen tip 2 diyabet gibi komorbid fiziksel hastalıklara ilişkin bakım verilmesinde kilit noktadadır (31,32). Bununla birlikte kronik ruhsal hastalığ 1 olan bireylere fiziksel sağlık bakımı sunmada psikiyatri hemşirelerinin sunduğu bakımda eksiklikler olduğu saptanmıştır (26). Psikiyatri hemşirelerinin kronik ruhsal hastalığı olan bireylere fiziksel sağlık bakımı vermeleriyle ilgili yapılan kalitatif bir çalışma sonucunda hemşireler, psikiyatri hastalarının fiziksel sağlık durumlarını algılayamadıklarını ve fiziksel sağlıklarına öncelik vermediklerini belirtmişlerdir. Aynı çalışmada psikiyatri hemşireleri fiziksel sağlık bakımı sunma konusundaki sorumluluk ve rollerinden emin olmadıklarını belirtmişlerdir (26).

Kronik ruhsal hastalığa ek olarak diyabeti olan bireylere sağlıklı yaşam biçiminin kazandırılması, motive edilmesi $(29,30)$ ve diyabet öz bakımlarını yapmaya cesaretlendirilmeleri bakımın önemli bir parçasıdır (30). Diyabet öz bakım davranışlarını yerine getirmek bireylerin kendi sorumluluğunda olsa da bu bireylere diyabet öz bakım davranışlarını kazandırmak, motive etmek, bu konuda eğitim ve danışmanlık yapmak hemşirenin sorumluluğundadır (30).

Kronik ruhsal hastalığa ek olarak diyabeti olan bireylere hemşireler tarafından verilen bakım önem kazanmaktadır. Psikiyatri hemşireleri bu hastaların diyabetlerini daha etkili yönetebilecekleri eğitici, danışman rollerini kullanarak girişimler planlamalı, hastaları bu konuda desteklemeli ve motive etmelidir. Multidisipliner ekibin bir parçası olan psikiyatri hemşirelerinin kronik ruhsal hastalığa ek olarak diyabet riski ya da diyabeti olan bireyler için uygulayabilecekleri hemşirelik girişimleri şunları içermektedir $(14,26,33)$;

- Hastadan detaylı bir tıbbi öykü alınmalıdır. Öyküde, önceki kardivasküler hastalık ve diyabet öyküsü, ailede kardiyovasküler hastalık ve diyabet öyküsü, sigara içme durumu saptanmalıdır. Diyabet riski açısından bel çevresi ve beden kitle indeksi ölçümü, açlık kan şekeri takibi, kan basıncı (iki kere ölçülmüş ve ortalaması alınmış) ve hekim istemine göre her 3-6 ayda bir HbA1c ölçümü yapılmalıdır.

- Psikiyatri alanında çalışanlar hemşire ve diğer sağlik profesyonelleri, tip 2 diyabet riskini değerlendirme ve yönetmede endokrinologlar ve alanında yetkin olan diyabet hemşireleri ile iş birliği içerisinde çalışmalı, gerektiğinde hastaları diyabet hemşiresine yönlendirmeli, özellikle atipik antipsikotik kullanan kronik ruhsal hastalığı olan bireylere tip 2 diyabet riski açısından aralıklı olarak taramalar yapılmalıdır.

- Özellikle önemli olan, pre-diyabet durumunu tanımlamaktır, böylece antipsikotik ilacın başlamasını izleyen süreçte diyabet riski izlenebilmektedir.

- Riskli hastalar yıllık kontrollerde kardiyovasküler risk faktörlerini, erken komplikasyon belirtilerini teşhis etmek, idrar albumin atılımı, serum kreatinin ölçümü, göz muayenesi ve ayak muayenesi yapılmak üzere hekime yönlendirilmelidir.

- Kardiyovasküler hastalık, diyabet ve buna bağlı ölüm riskindeki artışa etkisinin kanıtlanması nedeniyle hastalara aktif bir yaşam tarzının önerilmesi, sedanter yaşamın azaltılması, sağlıklı ve diyabete özgü beslenmenin teşvik edilmesi önemlidir. Bu nedenle sağlıklı yaşam biçimi girişimlerine ve tarama programlarına psikiyatri kliniklerinde öncelik verilmelidir.

- Sigara ve/veya alkol kullanan kronik ruhsal hastalığı olan bireylerin sigara ve/veya alkolü bırakmasına yönelik girişimler planlanmalı, hastalar bu konuda bilgilendirilmelidir.

- Diyabet tanısı alan ve özellikle insülin tedavisi gerektiren hastalar için ayak bakımı, kendi kan şekerini izleme, beslenme, fiziksel aktivite ve kontrollere gitmeyi içeren diyabet öz bakım eğitimi verilmelidir. Hastaların ayak bakımını ne sıklıkla ve nasıl yapacağı, kendi parmağından nasıl kan şekeri ölçümü yapacağı, kan şekeri değerini nasıl yorumlayacağı gibi konular 
eğitim oturumlarında hasta ile birlikte uygulamalı olarak anlatılarak hastanın kendi kendine bu bakımları yapabilme becerisi arttırılmalıdır. Egzersiz ve beslenmeye yönelik hastaya uygun yöntemler hasta ile birlikte planlanmalıdır. Hastalar ağır egzersizler yerine günlük en az $30 \mathrm{dk}$. tempolu yürüyüş yapma gibi daha uygulanabilir egzersizlere yöneltilebilir.

- Kronik ruhsal hastalığa ek olarak diyabeti olan bireylerin diyabet yönetiminde yaşadığı zorluklar ve engellere yönelik hastalara ve ailelerine destek olunmalı ve diyabet yönetiminde motivasyonlarını arttıracak girişimler planlanmalıdır. Bu doğrultuda psikiyatri hizmeti veren birimlerde hastalarla haftalık bireysel motivasyonel görüşme gibi tekniklerle ya da grup eğitimleri ile hastalar diyabet yönetimi konusunda eğitilebilir ve motive edilebilirler.

- Kronik ruhsal hastalığı olan bireylerin diyabet öz bakımını yapmalarını engelleyen halüsinasyon ve sanrı gibi psikiyatrik belirtiler ve sedasyon gibi psikiyatrik ilaç yan etkileri ile baş etmelerine yardımcı olunmalıdır. Bu semptomlar yönünden hastalar izlenmeli, kontrollere gelmesi desteklenmeli, hasta ve ailesine bu konuda bilgi verilmelidir.

- Kronik ruhsal hastalığı olan bireylerin klinik dışı yaşamlarında diyabet özbakım uyumlarını arttırmak, hastaların bu konuda motivasyonlarını sürdürmelerini sağlamak amacıyla tele-hemşirelik, web üzerinden eğitim, kısa mesajlar gibi yöntemler ile takip ve izlemleri yapılabilir.

\begin{abstract}
Sonuç
Sonuç olarak şizofreni, bipolar bozukluk ve şizoaffektif bozukluk gibi kronik ruhsal hastalığı olan bireylerde diyabet görülme oranı yüksektir. Bu durum daha çok değiştirilebilir yaşam biçimi girişimleri ile düzeltilebilmektedir. Kronik ruhsal hastalığı olan bireyler ile çalışan psikiyatri hemşirelerine diyabet riskini belirleme, diyabet yönetimine destek olma ve hastayı bu konuda teşvik etmede önemli rol düşmektedir. Sağlıklı yaşam biçimi davranışlarını ve diyabet öz bakımını geliştirme, bu hasta grubundaki sonuçları iyileştirmek için önemlidir. Psikiyatri alanında çalışan profesyoneller bu hastalarda görülen fiziksel sorunların özen ve dikkatle taranmasını, tedavi edilmesini ve izlenmesini sağlamalıdır. Kronik ruhsal hastalığı olan bireylerin fiziksel ve ruhsal sağlığının ele alınmasında bütüncül bir yaklaşım benimsenmelidir. Psikiyatri alanında çalışan hemşireler kronik ruhsal hastalığı olan bireylerin diyabet öz bakımlarını arttıracak kanıta dayalı girişimler planlamalı ve uygulamadırlar.
\end{abstract}

\title{
Bilgilendirme
}

Bu derlemeye yazarların katkı oranı beyanı şu şekildedir: fikir ve kavram SÇİ, NG; tasarım SÇİ; denetleme NG; literatür tarama SÇİ, NG; literatür verilerinin analizi ve yorumlaması SÇİ, NG; makalenin yazımı SÇİ; eleştirel düşünme NG. Derleme yazımı ile ilgili herhangi bir kurum ya da kuruluştan destek alınmamıştır.

$\mathrm{Bu}$ derleme araştırma ve bilimsel yayın etiğine uyularak yazılmıştır. Araştırmacılar arasında herhangi bir çıkar çatışması bulunmamaktadır.

\section{Kaynaklar}

1. Türkiye Diyabet Vakfi. Diyabet tanı ve tedavi rehberi 2017. 2017; 14-15.

2. Coşansu G. Diyabet: Küresel bir salgın hastalık. Okmeydanı Tıp Derg. 2015;31(ek sayı):1-6.

3. World Health Organization. World diabetes day. [online]. 2013;2(4): 123-124. URL:

http://who.int/healthtopics/diabetes. 10 Ekim 2013.

4. International Diabetes Federation. Diabetes atlas [online]. 2013;12-40. URL: https://www.idf.org/e-library/epidemiologyresearch/diabetes-atlas/19-atlas-6th-edition.html. 27 Mayıs 2013.

5. Türkiye İstatistik Kurumu. İstatistiklerle Türkiye [online]. 2015; 111-112. URL: http://www.tuik.gov.tr. 12 Haziran 2015.

6. Wykes TL, Lee AA, Bourassa K, Kitchen KA, McKibbin CL. Diabetes knowledge among adults with serious mental illness and comorbid diabetes mellitus. Arch Psychiatr Nurs. 2017;31(2):190-6.

7. İstek N, Karakurt P. Global bir sağlık sorunu: tip 2 diyabet ve öz-bakım yönetimi. JAREN. 2018;4(3):179-82.

8. Vaez K, Diegel-Vacek L, Ryan C, Martyn-Nemeth P. Evaluating diabetes care for patients with serious mental illness using the chronic care model. Heal Serv Res Manag Epidemiol. 2017;4:1-7.

9. Vancampfort D, Correlli CU, Gallin B, Probst M, De Hert M, Ward PB, et al. Diabetes mellitus in people with schizophrenia, bipolar disorder and major depressive disorder: a systematic review and large scale meta- analysis. World Psychiatry. 2016;15(2):166-74.

10. Liu NH, Daumit GL, Dua T, Aquila R, Charlson F, Cuijpers P, et al. Excess mortality in persons with severe mental disorders: a multilevel intervention framework and priorities for clinical practice, policy and research agendas. World Psychiatry. 2017;16:30-40.

11. Kurdyak P, Vigod S, Duchen R, Jacob B, Stukel T, Kiran T. Diabetes quality of care and outcomes: Comparison of individuals with and without schizophrenia. Gen Hosp Psychiatry. 2017;46:7-13.

12. Holt RIG. Diabetes in psychiatric disease. Med (United Kingdom). 2015;43(1):51-3.

13. Vinogradova Y, Coupland C, Hippisley-Cox J, Whyte S, Penny C. Effects of severe mental illness on survival of people with diabetes. Br J Psychiatry. 2010;197(4):272-7.

14. Stubbs B, Vancampfort D, De Hert M, Mitchell AJ. The prevalence and predictors of type two diabetes mellitus in people with schizophrenia: a systematic review and comparative meta-analysis. Acta Psychiatr Scand. 2015;132(2):144-57.

15. Subashini R, Deepa M, Padmavati R, Thara R, Mohan V. Prevalence of diabetes, obesity, and metabolic syndrome in subjects with and without schizophrenia (CURES-104). J Postgrad Med. 2011;57(4); 272-277.

16. Leopold K, Reif A, Haack S, Bauer M, Bury D, Löffler A, et al. Type 2 diabetes and pre-diabetic abnormalities in patients with bipolar disorders. J Affect Disord. 2016;189:240-245. 
Derleme

17. Chen S, Chien Y, Kang C, Jeng C, Chang W. Comparing self-efficacy and self-care behaviours between outpatients with comorbid schizophrenia and type 2 diabetes and outpatients with only type 2 diabetes. J Psychiatr Ment Health Nurs. 2014;21(5):414-422.

18. Scott D, Happell B. The high prevalence of poor physical health and unhealthy lifestyle behaviours in individuals with severe mental illness. Issues Ment Health Nurs. 2011;32(9):589-97.

19. Tek C, Kucukgoncu S, Guloksuz S, Woods SW, Srihari VH, Annamalai A. Antipsychotic-induced weight gain in firstepisode psychosis patients: a meta-analysis of differential effects of antipsychotic medications. Early Interv Psychiatry. 2016;10(3):193-202.

20. Holt RIG. Association between antipsychotic medication use and diabetes. Curr Diab Rep. 2019;19(10).

21. Yılmaz S, Şahin G, Buzlu S. Psikofarmakolojik Tedaviler ve Fiziksel Sağlık. İçinde Bilgin H, Ruh Sağlı̆̆ ve Psikiyatri Hemşireliğinde Fiziksel Sağlık. 1.Basım. Türkiye Klinikleri, Ankara; 2019:19-29.

22. Correll CU, Detraux J, Lepeleire J De, De Hert M. Effects of antipsychotics, antidepressants and mood stabilizers on risk for physical diseases in people with schizophrenia, depression and bipolar disorder. World Psychiatry. 2015;14:119-136.

23. Yoon JM, Cho E, Lee H, Park SM. Antidepressant use and diabetes mellitus risk: a meta-analysis. Korean J Fam Med. 2013;34(4):228-240.

24. Mangurian C, Newcomer JW, Vittinghoff E, Creasman JM, Knapp P, Fuentes-Afflick E, et al. Diabetes screening among underserved adults with severe mental illness who take antipsychotic medications. JAMA Intern Med. 2015;175(12):1977-1979.

25. Ince SÇ, Günüşen NP, Özerdem A, Özışık S. Diabetes self-care views of individuals with severe mental illness and comorbid type 2 diabetes and of those only with type 2 diabetes. Arch Psychiatr Nurs. 2017;31(4): 386-393.

26. Çelik Ince S, Partlak Günüşen N, Serçe Ö. The opinions of Turkish mental health nurses on physical health care for individuals with mental illness: A qualitative study. J Psychiatr Ment Health Nurs. 2018;25(4):245-57.

27. De Hert M, Cohen D, Bobes J, Cetkovich-Bakmas M, Leucht S, Ndetei DM, et al. Physical illness in patients with severe mental disorders. II. Barriers to care, monitoring and treatment guidelines, plus recommendations at the system and individual level. World Psychiatry. 2011;10(2):138-51.

28. Mulligan K, McBain H, Lamontagne-Godwin F, Chapman J, Haddad M, Jones J, et al. Barriers and enablers of type 2 diabetes self-management in people with severe mental illness. Heal Expect. 2017;20(5):1020-30.

29. Hultsjö SM, Hjelm K. Organizing care for persons with psychotic disorders and risk of or existing diabetes mellitus type 2. J Psychiatr Ment Health Nurs. 2012;19(10):891-902.

30. Meetoo DD. Dangerous liaisons: the relationship between schizophrenia and diabetes. J Diabetes Nurs. 2013;17(3):104111.

31. Kayar Erginer D, Partlak Günüşen N. Kronik psikiyatri hastalarının fiziksel sağlık durumu: ihmal edilen bir alan. DEUHFED. 2013;6(3):159-64.

32. Bradshaw T, Pedley R. Evolving role of mental health nurses in the physical health care of people with serious mental health illness. Int J Ment Health Nurs. 2012;21(3):266-73.

33. WHO Guidelines. Management of physical health conditions in adults with severe mental disorders [online]. 2018:1-94 URL: http://apps.who.int/iris/bitstream/handle/10665/275718/9789241550383-eng.pdf. 07 Kasım 2018. 